\title{
Ovarian Conservation in Patients with Early Stage Endometrial Carcinoma (EC) as a Safe Alternative to Oophorectomy
}

\author{
Walid A. Abdelsalam¹, Mohamed Fathy Abohashim¹, Doaa Mandour², Taha A. Baiomy ${ }^{3}$, \\ Ibrahim Heggy ${ }^{3}$ \\ ${ }^{1}$ Department of Gynecology and Obstetrics, Faculty of Medicine, Zagazig University, Zagazig, Egypt \\ ${ }^{2}$ Department of Clinical Oncology and Nuclear Medicine, Faculty of Medicine, Zagazig University, Zagazig, Egypt \\ ${ }^{3}$ Department of General Surgery, Faculty of Medicine, Zagazig University, Zagazig, Egypt
}

\section{Email address:}

Walid_Abdallah@gmail.com (W. A. Abdelsalam)

\section{To cite this article:}

Walid A. Abdelsalam, Mohamed Fathy Abohashim, Doaa Mandour, Taha A. Baiomy, Ibrahim Heggy. Ovarian Conservation in Patients with Early Stage Endometrial Carcinoma (EC) as a Safe Alternative to Oophorectomy. Journal of Surgery. Vol. 8, No. 2, 2020 , pp. $71-75$. doi: $10.11648 /$ j.js.20200802.16

Received: February 25, 2020; Accepted: March 6, 2020; Published: April 17, 2020

\begin{abstract}
Background: Premenopausal females having early-stage EC have a favorable prognosis. The guidelines of surgical treatment of EC have not been modified and it consists of total hysterectomy, bilateral salpingo-oophrectomy, pelvic and para-aortic lymphadenectomy, regardless of patients' age or EC stage. The drawbacks of performing bilateral BSO are induction of surgical premature menopause which subsequently disturbs physical and psychosexual life in addition to increasing risk of diseases of the cardiovascular system and bone fractures. The aim of our study was to demonstrate if performing BSO in premenopausal females patients with early stage EC had survival benefits and improving long-term outcomes or not. Patients and methods; we included sixty EC patients and we have performed ovarian conservation in $30(50 \%)$ of them, and performed BSO in the remaining 30 patients we have followed our patients for 5 years from December 2014 to December 2019. Results: Age of patients with ovarian conservation was younger than patients with BSO ( $\mathrm{p}=0.032)$, have smaller tumor size $(\mathrm{p}=0.02)$, higher degree of tumor differentiation $(\mathrm{p}=0.025)$, less incidence of myomertrial invasion $(\mathrm{p}=0.004)$, less liability of lymphovascular invasion $(\mathrm{p}=0.001)$, more liability to endometrioid histopathological subtype $(p=0.003)$, and earlier stage $(p=0.009)$ than patients with BSO. There were no significant differences between both studied groups regarding recurrence of the tumor, recurrence free survival and overall survival rates. Conclusion: The current study tried to highlight the benefits of a more conservative approach by ovarian preservation in surgical management and staging of EC patients diagnosed in the early stage in young premenopausal women.
\end{abstract}

Keywords: Endometrial Cancer, Conservation of Ovaries, Survival

\section{Introduction}

Endometrial carcinoma is mostly a postmenopausal female's malignancy, but in about quarter of patients who were diagnosed with EC was premenopausal. EC incidence in premenopausal females under the age of forty years became about $15 \%$ and it has been elevated recently [1]. Premenopausal females having early-stage EC have a favorable prognosis, with their 5 year overall survival rate is found to be more than $90 \%$. Younger females are mostly diagnosed early with earlier stage EC than older women, and their overall survival rate is better [2]. But, the guidelines of surgical treatment of EC have not been modified and it consists of total hysterectomy, bilateral salpingooophrectomy, pelvic and para-aortic lymphadenectomy, regardless of patients' age or EC stage [1]. The roles of excision of both ovaries in patients with EC are; excluding occult ovarian metastases, decreasing estrogen secretion as EC was found to be an estrogen-dependent malignancy. But, there are controversies regarding the need of aggressive surgical management by removing both ovaries or performing lymphadenectomy, especially in young females 
diagnosed with early stage EC [3]. The drawbacks of performing bilateral BSO are induction of surgical premature menopause which subsequently disturbs physical and psychosexual life in addition to increasing risk of diseases of the cardiovascular system and bone fractures [4]. Also performing BSO might be not needed in females having early-stage EC due to low incidence of metastases to the ovaries that was found to be only about $5 \%$ of all reported cases [3].

Since there were no sufficient prospective studies regarding conserving ovaries or performing oophorectomy in EC patients. We performed the current study to demonstrate if performing $\mathrm{BSO}$ in premenopausal females patients with early stage EC had survival benefits and improving long-term outcomes or not.

\section{Materials and Methods}

The present study was approved by the local institutional review board of faculty of medicine, Zagazig University after having a written consent from included patients in the study. We included sixty EC patients and we have performed ovarian conservation in $30(50 \%)$ of them, and performed BSO in the remaining 30 patients we have followed our patients for 5 years from December 2014 to December 2019.

\subsection{Inclusion Criteria}

Patients who were previously histopathologically confirmed to have EC.

Patents with early stage endometrioid EC and nonendometrioid EC stage I.

\subsection{Exclusion Criteria}

Patients with no confirmed diagnosis.

Patients with advanced EC.

Patients with clinical or radiological evidence of lymph nodes or distant metastases.
Patients having malignancy in other site.

We collected patients data during the period of the study including; age at EC diagnosis, patients gravity and parity, preoperative histopathological diagnosis, subtype, grade and stage of the tumor, lymphovascular, myometrial and cervical invasion, causes of ovarian conservation, history of previous operation or EC recurrence, follow-up data for progression, recurrence, response to therapy, disease-free survival and overall survival rates.

EC stage of tumor was made depending on clinical and radiological evaluation; we considered ovaries, tubes and lymph nodes as negative for metastases based on intraoperative evaluation.

\subsection{Statistical Analysis}

Survival analysis was evaluated using Kaplan Meier methods, and was compared using the log-rank test. A p value $<0.05$ was considered significant. All statistical analyses were made using SPSS version 21 software (SPSS, Chicago, IL, USA).

\section{Results}

Demographic, histopathological and clinical findings of included patients were detailed in table 2 .

Age of patients with ovarian conservation was younger than patients with BSO $(\mathrm{p}=0.032)$, have smaller tumor size $(p=0.02)$, higher degree of tumor differentiation $(p=0.025)$, less incidence of myomertrial invasion $(p=0.004)$, less liability of lympho-vascular invasion $(p=0.001)$, more liability to endometrioid histo-pathological subtype $(\mathrm{p}=0.003)$, and earlier stage $(\mathrm{p}=0.009)$ than patients with BSO. There were no significant differences between both studied groups regarding recurrence of the tumor, recurrence free survival and overall survival rates. Tables1 and 2, figure 1.

Table 1. Correlations between performing ovarian conservation and BSO in studied patients.

\begin{tabular}{|c|c|c|c|c|}
\hline \multirow{3}{*}{ Variables } & \multirow{3}{*}{$\begin{array}{l}\text { Total } \\
\mathrm{N}=60(\%)\end{array}$} & \multicolumn{2}{|l|}{ Management techniques } & \multirow{3}{*}{$\mathbf{p}$} \\
\hline & & Ovarian Conservation & oophorectomy & \\
\hline & & $\mathrm{N}=\mathbf{3 0}(\%)$ & $\mathrm{N}=30(\%)$ & \\
\hline \multicolumn{5}{|l|}{ Age (years): } \\
\hline Mean \pm SD & $47.93 \pm 10.57$ & $32.43 \pm 11.2$ & $50.33 \pm 5.29$ & 0.032 \\
\hline \multicolumn{5}{|l|}{ Tumor size } \\
\hline$\leq 2$ & $30(33.3)$ & $20(50)$ & $10(50)$ & \multirow{2}{*}{0.02} \\
\hline$>2$ & $30(50)$ & $10(53.3)$ & $20(46.7)$ & \\
\hline \multicolumn{5}{|l|}{ Myometrial invasion } \\
\hline Absent & $30(33.3)$ & $20(50)$ & $10(50)$ & \multirow{2}{*}{0.004} \\
\hline Present & $30(50)$ & $10(53.3)$ & $20(46.7)$ & \\
\hline \multicolumn{5}{|c|}{ Lympho-vascular invasion } \\
\hline Absent & $35(33.3)$ & $25(50)$ & $10(50)$ & \multirow{2}{*}{0.001} \\
\hline Present & $25(50)$ & $5(53.3)$ & $20(46.7)$ & \\
\hline \multicolumn{5}{|c|}{ Histopathological type: } \\
\hline Endometriod & $40(16.7)$ & $25(70)$ & $15(30)$ & \multirow{3}{*}{0.003} \\
\hline Non-endometrioid & $20(33.3)$ & $5(25)$ & $15(75)$ & \\
\hline Grade: & & & & \\
\hline
\end{tabular}




\begin{tabular}{|c|c|c|c|c|}
\hline \multirow{3}{*}{ Variables } & \multirow{3}{*}{$\begin{array}{l}\text { Total } \\
\mathrm{N}=60(\%)\end{array}$} & \multicolumn{2}{|l|}{ Management techniques } & \multirow{3}{*}{$\mathbf{p}$} \\
\hline & & \multirow{2}{*}{$\begin{array}{l}\text { Ovarian Conservation } \\
\mathbf{N}=\mathbf{3 0}(\%)\end{array}$} & \multirow{2}{*}{$\begin{array}{l}\text { oophorectomy } \\
\mathbf{N}=\mathbf{3 0}(\%) \\
\end{array}$} & \\
\hline & & & & \\
\hline High grade & $20(33)$ & $6(41.7)$ & $14(58.3)$ & \multirow{3}{*}{0.025} \\
\hline Low grade & $40(67)$ & $24(69)$ & $16(31)$ & \\
\hline \multicolumn{4}{|l|}{ FIGO stage: } & \\
\hline IA & $15(18.3)$ & $11(45.5)$ & $4(54.5)$ & \multirow{4}{*}{0.009} \\
\hline IB & $20(13.3)$ & $14(75)$ & $6(25)$ & \\
\hline IIA & $15(18.3)$ & $8(72.7)$ & $7(27.3)$ & \\
\hline IIB & $10(18.3)$ & $3(18.3)$ & $7(18.3)$ & \\
\hline
\end{tabular}

Table 2. Correlations between performing ovarian conservation and BSO in studied patients regarding outcome.

\begin{tabular}{|c|c|c|c|c|}
\hline \multirow{3}{*}{ Variables } & \multirow{3}{*}{$\begin{array}{l}\text { Total } \\
\mathrm{N}=60(\%)\end{array}$} & \multicolumn{2}{|c|}{ Management techniques } & \multirow{3}{*}{$\mathbf{p}$} \\
\hline & & Ovarian conservation & oophorectomy & \\
\hline & & $\mathrm{N}=\mathbf{3 0}(\%)$ & $\mathrm{N}=\mathbf{3 0}(\%)$ & \\
\hline \multicolumn{5}{|c|}{ Postoperative complications: } \\
\hline Absent & $44(73.3)$ & $25(56.8)$ & $19(43.2)$ & \multirow{2}{*}{0.08} \\
\hline present & $16(26.7)$ & $5(31.2)$ & $11(68.8)$ & \\
\hline \multicolumn{5}{|c|}{ Relapse $(\mathrm{n}=56)$ : } \\
\hline Absent & $34(60.7)$ & $20(58.8)$ & $14(41.2)$ & \multirow{2}{*}{0.101} \\
\hline Present & $26(39.3)$ & $10(36.4)$ & $16(63.6)$ & \\
\hline \multicolumn{5}{|l|}{ Death } \\
\hline No & $46(76.7)$ & $25(54.3)$ & $21(45.7)$ & \multirow{2}{*}{0.222} \\
\hline Yes & $14(23.3)$ & $5(35.7)$ & $9(64.3)$ & \\
\hline \multicolumn{5}{|c|}{ Recurrence free survival: } \\
\hline Mean \pm SD & $50.7 \pm 8.15$ & $52.86 \pm 7.28$ & $48.54 \pm 8.52$ & \multirow{2}{*}{0.07} \\
\hline Range & $30-60$ & $35-60$ & $30-60$ & \\
\hline \multicolumn{5}{|c|}{ Overall survival: } \\
\hline Median & $53.79 \pm 5.71$ & $55.23 \pm 4.66$ & $51.97 \pm 6.52$ & \multirow{2}{*}{0.09} \\
\hline Range & $39-60$ & $45-60$ & $39-60$ & \\
\hline
\end{tabular}

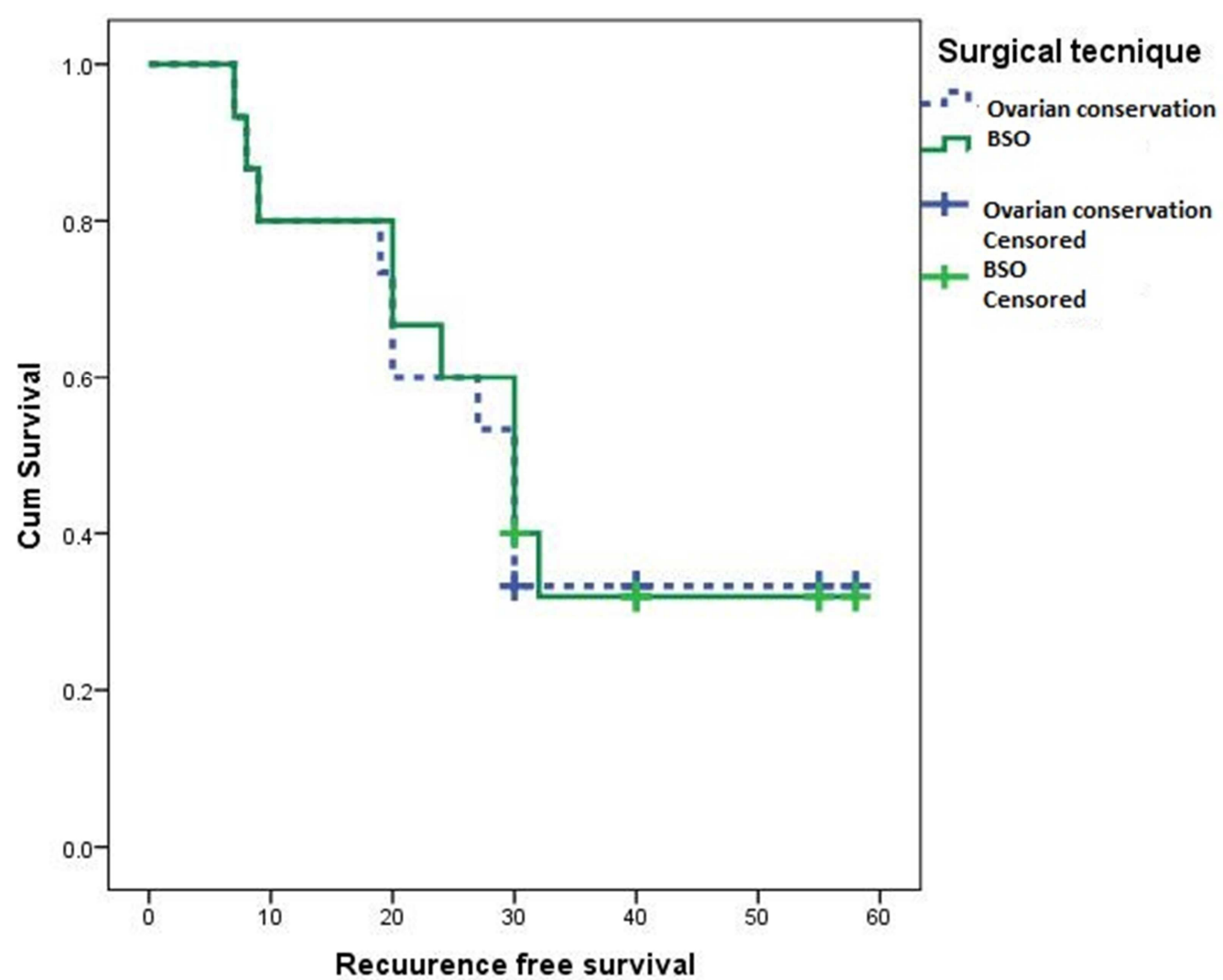

Figure 1. Kaplan Meier plot showing recurrence free survival (RFS) among studied patients. 


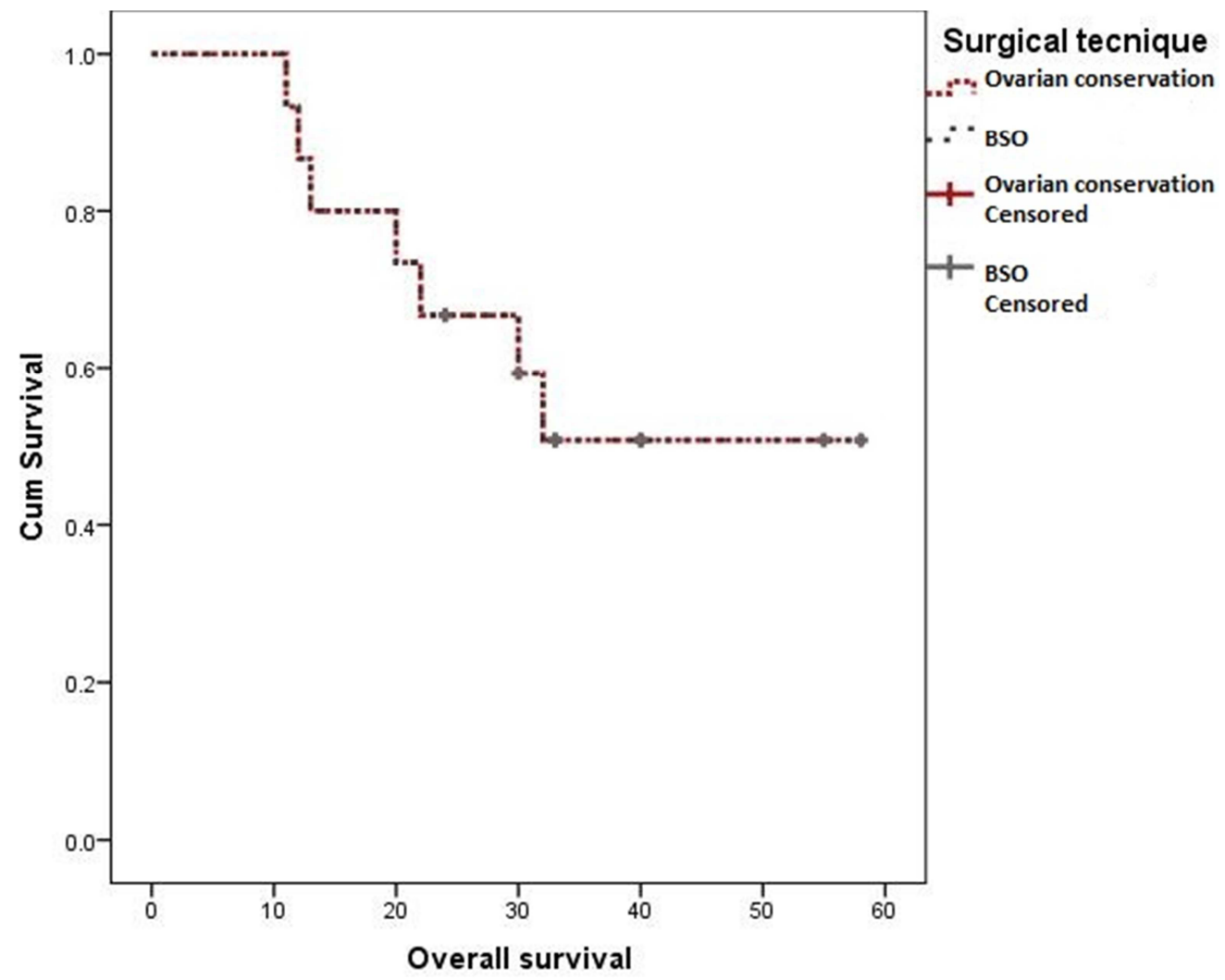

Figure 2. Kaplan Meier plot showing overall survival (OS) rate among studied patients.

\section{Discussion}

EC in young premenopausal women mostly well differentiated, diagnosed in the early stages and has a prognosis favorable with an expected long survival rates [1].

Standard surgical management strategies which included BSO in addition to hysterectomy and lymphadenectomy leading to induction of premature surgical menopause which leads to increasing rates of cardiovascular diseases, osteoporosis, bone fractures and worsens young females quality of life [5]. Nowadays safety of preservation of both ovaries is modified as followed: there is low risk of a coexisting ovarian cancer in patients with EC in adition to the neglected stimulatory effects of estrogen production by preserved ovaries in cases of residual microscopic foci of EC.

In the current study we found that conservation of ovaries in EC patients have many advantages without increasing risks of recurrence or subsequent ovarian cancer.

Lin et al. [6] and Pan et al. [7], reported that neglected number of EC patients having coexisting ovarian metastases in EC patients having stage I. Walsh et al. [8] reported different results that $25 \%$ of young females with EC had coexisting ovarian malignancies which showed that great cautions must be undertaken if we have considered preservation of ovaries in young women even with early stages EC. Other studies stated that risks of estrogen stimulation on remaining microscopic foci of EC are still doubtful [9]. On the contrary; Lyu et al., [5], showed that estrogen replacement treatment have not increased the risks of recurrence or death in EC survivors which is in line with our results about safety of ovarian preservation in EC patients as In our study, ovarian preservation have not affected recurrence or survival rates, which is similar to previous studies [5, 10-13].

Lau et al., 2015 found lower rates of recurrence rate (1.6\%) in groups of EC patients underwent ovarian preservation.

Moreover Gonthier et al. [14] found that preserving both ovaries have not been associated with reduction in the survival rates even in females having grades 2 or 3 EC. A recent meta-analysis about such issue stated that ovarian preservation was even related to favorable overall survival rate and have not been associated with decreasing recurrencefree survival rate in premenopausal women having early stage EC [1, 15]. A recent report stated that ovarian preservation is safely made to premenopausal females' patients having stage Ia EC [10]. Lyu et al., [5], showed that there were no significant differences in recurrence-free survival rate in stage Ia EC patients having ovarian preservation and in those patients with $\mathrm{BSO}$ which denoted that ovarian preservation could be considered a safe alternative to removing both ovaries in EC patients diagnosed early in in premenopausal patients after a detailed preoperative clinical and radiological assessment.

Lau et al., [3], stated that preserving both ovaries is a suitable alternative in EC patients with early-stage disease, and it will not increase EC-related mortality. 


\section{Conclusions}

The current study tried to highlight a more conservative approach in surgical management and staging of EC patients diagnosed in the early stage in young premenopausal women. But, the performing ovarian preservation must be highly individualized according to patients consent. Patients who desired to have ovarian preservation must have a detailed explanation of the risks. Genetic tests are highly needed in patients with a positive family history of EC, breast and ovarian cancer.

\section{Strengths of the Study}

The current study is a prospective study which explored an important point of research.

\section{Limitations of the Study}

Relatively small number of patients and short follow-up time.

Disclosure Statement: authors declared no conflicts of interest.

Abbreviations.

\section{Endometrial Carcinoma (EC)}

Total abdominal hysterectomy (TAH).

Bilateral salpigooophrectomy (BSO).

Institutional review board (IRB).

\section{References}

[1] Jia P and Zhang Y. Ovarian preservation improves overall survival in young patients with early-stage endometrial cancer Oncotarget, 2017, Vol. 8, (No. 35), pp: 59940-59949.

[2] Siegel RL, Miller KD, Jemal A. Cancer statistics, 2019. CA Cancer J Clinic. (2019) 69 (Suppl. 12): 7-34.

[3] Lau HY, Chen MY, Ke YM, et al. Outcome of ovarian preservation during surgical treatment for endometrial cancer: a Taiwanese Gynecologic Oncology Group study. Taiwan J Obstet Gynecol 2015; 54: 532-536.

[4] Lee TS, Kim JW, Kim TJ, Cho CH, Ryu SY, Ryu HS, et al.
Ovarian preservation during the surgical treatment of early stage endometrial cancer: a nationwide study conducted by the Korean Gynecologic Oncology Group. Gynecol Oncol 2009; 115: 26-31.

[5] Lyu T, Guo L, Chen X, Jia N, Gu CH, Zhu M et al. Ovarian preservation for premenopausal women with early-stage endometrial cancer: a Chinese retrospective study Journal of International Medical Research 2019; 47 (6) 2492-2498.

[6] Lin KY, Miller DS, Bailey AA, et al. Ovarian involvement in endometrioid adenocarcinoma of uterus. Obstet Gynecol 2015; 138: 532-535.

[7] Pan Z, Wang X, Zhang X, et al. Retrospective analysis on coexisting ovarian cancer in 976 patients with clinical stage I endometrial carcinoma. J Obstet Gynaecol Res 2011; 37: 352-358.

[8] Walsh C, Holschneider C, Hoang Y, Tieu K, Karlan B, Cass I. Coexisting ovarian malignancy in young women with endometrial cancer. Obstet Gynecol 2005; 106: 693-9.

[9] Barakat RR, Bundy BN, Spirtos NM, Bell J, Mannel RS. Randomized doubleblind trial of estrogen replacement therapy versus placebo in stage I or II endometrial cancer: a Gynecologic Oncology Group Study. J Clin Oncol 2006; 24: 587-92.

[10] Li J, Zhu Q, Yang B, et al. Risk factors for ovarian involvement in young and premenopausal endometrioid endometrial cancer patients. Eur J Obstet Gynecol Reprod Biol 2018; 222: 151-154.

[11] Hou T, Sun Y, Li J, et al. The safety of ovarian preservation in stage $\mathrm{i}$ endometrial endometrioid adenocarcinoma based on propensity score matching. Comb Chem High Throughput Screen 2017; 20: 647-655.

[12] Matsuo K, Machida H, Shoupe D, et al. Ovarian conservation and overall survival in young women with early-stage cervical cancer. Obstet Gynecol 2017; 129: 139-151.

[13] Wright JD, Jorge S, Tergas AI, et al. Utilization and outcomes of ovarian conservation in premenopausal women with endometrial cancer. Obstet Gynecol 2016; 127: 101-108.

[14] Gonthier C, Trefoux-Bourdet A and Koskas M. Impact of conservative managements in young women with grade 2 or 3 endometrial adenocarcinoma confined to the endometrium. Int J Gynecol Cancer 2017; 27: 493-499.

[15] Gu H, Li J, Gu Y, et al. Survival impact of ovarian preservation on women with earlystage endometrial cancer: a systematic review and meta-analysis. Int $\mathrm{J}$ Gynecol Cancer 2017; 27: 77-84. 